\title{
Planar diffusion to macro disc electrodes - What electrode size is required for the Cottrell and Randles-Sevcik equations to apply quantitatively?
}

\author{
Kamonwad Ngamchuea, Shaltiel Eloul, Kristina Tschulik, Richard G Compton*
}

Department of Chemistry, Physical \& Theoretical Chemistry Laboratory, Oxford University, South Parks Road, Oxford, OX1 3QZ, United Kingdom

*corresponding author: Richard G. Compton, PTCL, Department of Chemistry, University of Oxford, South Parks Road, Oxford, OX1 3BW, U.K.

Email: richard.compton@ chem.ox.ac.uk. Tel: +44 (0) 1865275957 Fax: +44 (0) 1865275410

\section{Key Words:}

Mass transport, one-dimensional planar diffusion, Cottrell equation, Randles-Sevcik equation, chronoamperometry, cyclic voltammetry

\begin{abstract}
Simulations and experiments are reported which investigate the size of a macro disc electrode necessary to quantitatively show the chronoamperometric or voltammetric behaviour predicted by the Cottrell equation or the Randles-Sevcik equation on the basis of exclusive one-dimensional diffusional mass transport. For experimental time scales of several seconds, the contribution of radial diffusion is seen to be measurable even for electrodes of millimetres in radius. Recommendations on the size of macro electrodes for quantitative study are given and should exceed $4 \mathrm{~mm}$ radius in aqueous solution.
\end{abstract}

\section{Introduction}

\footnotetext{
${ }^{\dagger}$ Paper submitted for the 'Fletcher Festschrift' issue of Journal of Solid State Electrochemistry in admiration of an outstanding scientist and much valued electrochemistry colleague.
} 
The use of microelectrodes for the best-practice measurement of electrochemically derived data, such as heterogeneous rate constants, diffusion coefficients, fast coupled homogeneous reaction kinetics and analytical considerations, is well-established. This approach is largely based on the pioneering work of Amatore [1,2] and was further implemented by Bond [3,4] and others [5, 6]. Recently - and partly driven by the need to interrogate the diverse, complex and ever increasingly imaginative methods for possible energy conversion and storage as well as for analysis - there has been a renaissance in macro electrode measurements both employing rotating disc electrodes [7, 8], but also, and especially, cyclic voltammetry using macro electrodes [9], as originally introduced by the classical work of Nicholson and Shain $[10,11]$.

The simplicity of using macro electrodes, other than the practical ease of size, lies in the assumption that diffusional transport to the electrode surface will be planar and one-dimensional. Thus, and usually in contrast to microelectrodes, theoretical equations can often be derived in mathematically analytical forms for the purpose of comparison with experiments. Thus, the current-time (I-t) response resulting from a potential step from zero current to diffusion-limited conditions applied to the sample redox process:

$\mathrm{A} \pm \mathrm{e}^{-} \leftrightarrows \mathrm{B}$

is given by the Cottrell equation known to all electrochemists [12]:

$I=\frac{\mathrm{F} A \sqrt{D}}{\sqrt{\pi t}}[A]_{\mathrm{bulk}}$

where $D$ is the diffusion coefficient, $[A]_{\text {bulk }}$ the bulk concentration of species $\mathrm{A}$ in the solution, $\mathrm{F}$ is the Faraday constant and $A$ the electrode area (for a disc of radius $r_{\mathrm{e}}$ the area $A=\pi r_{\mathrm{e}}^{2}$ ).

Similarly, assuming that the redox couple A/B is electrochemically reversible under the prevailing mass transport conditions, the peak current $I_{P}$ for cyclic voltammetry is predicted to be:

$$
I_{P}=0.446 \mathrm{~F} \pi r_{\mathrm{e}}^{2} \sqrt{\frac{\mathrm{F} D v}{\mathrm{R} T}}[A]_{\mathrm{bulk}}
$$

where $v$ is the scan rate, $T$ is the temperature and $\mathrm{R}$ the universal gas constant[13]. Both equations (1) and (2) result from solving Fick's laws of diffusion $[14,15]$ in one spatial dimension with the appropriate boundary conditions.

Given the renaissance of macro electrode measurements, it is interesting to consider under which conditions equations (1) and (2) can be applied quantitatively, not least since it has recently been asserted 
that macro electrode experiments may lead to a great diversity of results when applied to the same system, but by different groups [16-18]. Moreover, this variation has been such as to apparently stimulate the introduction of elaborate new techniques such as FFT (Fast Fourier Transformation) voltammetry in an attempt to improve the reproducibility $[19,20]$.

Among the primary features for the applicability of equation (1) and (2) are the need for tight thermostating, application of the appropriate potential range such that the voltage seen is not reversed prematurely relative to a cyclic voltammetry peak [13], the avoidance of using second or later scan data, the avoidance of natural convection [21,22] the recognition that the use of a digital potentiostat can broaden voltammetric measurements [23] and the need to ensure that the electrode is flat and neither rough nor porous $[24,25]$. However, one further very simple consideration has to be addressed, namely how large does the electrode have to be in order to quantitatively comply with equations (1) and (2)? In other words what is the contribution of radial diffusion (often referred to as 'edge effect') to chronoamperometry and cyclic voltammetry carried out at macro electrodes? Answering these questions is the aim of this present note and will be approached from both simulation and experimental perspectives.

\section{Experimental}

\section{Chemicals and electrochemical setup}

The electrolyte used was an aqueous solution of $9.50 \mathrm{mM}$ of potassium ferrocyanide $\mathrm{K}_{4}\left[\mathrm{Fe}(\mathrm{CN})_{6}\right]$ (Lancaster, UK) and $0.50 \mathrm{M}$ potassium nitrate $\mathrm{KNO}_{3}(\mathrm{BDH})$. This solution was prepared by dissolving the respective analytical grade chemicals in high-purity water (Millipore, resistivity not less than $18.2 \mathrm{M} \Omega \mathrm{cm}$ at $25^{\circ} \mathrm{C}$ ).

Electrochemical measurements were performed using a three electrode setup comprising a carbon rod counter electrode, a saturated calomel reference electrode (SCE, $E=0.241 \mathrm{~V}$ vs standard hydrogen electrode, BASi Inc.) and either one of two differently sized glassy carbon working electrodes (BASi Inc.). The two working electrodes were sized to $1.49 \pm 0.02 \mathrm{~mm}$ and $0.78 \pm 0.03 \mathrm{~mm}$ in radius using optical microscopy (Unicam Instruments LTD). The working electrodes were first polished to a mirror surface using diamond spray (Kemet, particle size $1.0 \mu \mathrm{m}$ and $0.3 \mu \mathrm{m}$ ) and then sonicated in high-purity water for 1 minute prior to each measurement. During electrochemical measurements tight thermostating of the entire electrochemical cell to under $\pm 0.2{ }^{\circ} \mathrm{C}$ was ensured by placing the cell in a thermostated water bath 
inside a thermostated Faraday cage. All measurements were performed in stagnant solutions using a $\mu$ Autolab III (Metrohm) potentiostat.

\section{$\underline{\text { Diffusion coefficient measurements }}$}

Temperature-dependent diffusion coefficients of $\left[\mathrm{Fe}(\mathrm{CN})_{6}\right]^{4-}$ in the used electrolyte were determined by steady-state voltammetry at a platinum micro disc working electrode (radius $=4.8 \mu \mathrm{m}$, calibrated using ruthenium hexa-amine) in the temperature range from $24.0^{\circ} \mathrm{C}$ to $28.0^{\circ} \mathrm{C}$. The potential was scanned from $-0.15 \mathrm{~V}$ to $0.6 \mathrm{~V}$ vs SCE at a scan rate of $25 \mathrm{mVs}^{-1}$.

\section{Chronoamperometry}

To quantify the effect of radial diffusion on chronoamperometry at conventional commercial 'macro' electrodes the oxidation of ferrocyanide at two differently sized glassy carbon electrodes was studied under mass transport limited conditions. For this purpose, the applied potential was changed from $-0.2 \mathrm{~V}$ vs SCE to $0.35 \mathrm{~V}$ vs. SCE in a single step and the resulting current was recorded for 10 seconds. For each electrode size three separate chronoamperometric experiments were performed. Blank measurements were acquired in a solution of $0.50 \mathrm{M} \mathrm{KNO}_{3}$ and were subtracted from the chronoamperograms obtained in the presence of ferrocyanide to remove capacitive contributions from the Faradaic signal.

Convection of the electrolyte was kept at an experimental minimum by avoiding temperature gradients and mechanical perturbation of the electrolyte as well as by restricting the experimental time scale to short durations (10 s) in order to avoid natural convection.

\section{$\underline{\text { Simulation }}$}

A simulation for a cyclic voltammetry measurement was carried out for an ideal reduction/oxidation system containing a disc electrode with varied radius. In the model the transport of the electrochemical species in solution is described for fully supported electrolyte conditions. The thus obtained diffusion controlled system was solved numerically using Fick's second law in a two-dimensional cylindrical space [26]:

$\frac{\partial[A]}{\partial t}=D\left(\frac{\partial^{2}[A]}{\partial r^{2}}+\frac{1}{r} \frac{\partial[A]}{\partial r}+\frac{\partial^{2}[A]}{\partial z^{2}}\right)$ 
for a representative $D$ of $10^{-9} \mathrm{~m}^{2} \mathrm{~s}^{-1}$ and an initial concentration of $[\mathrm{A}]=1 \mathrm{mM}$. A reversible boundary condition was applied on the disc electrode surface to relate the potential $V$ to the surface concentrations of the oxidant $c_{\text {ox }}$ and the reductant $c_{\text {red }}$ were described by the Nernst expression:

$$
\left(V-E_{f}^{\ominus}\right) \frac{F}{R T}=\ln \left(\frac{c_{o x}}{c_{r e d}}\right)
$$

$E_{f}^{\ominus}$ is the formal potential. Insulation boundary conditions are used for the cell walls and axial symmetry condition at $r=0$. We also simulated a 'macro' case of an infinite disc radius using a one dimensional system. In this case the Fick's second law follows:

$\frac{\partial[A]}{\partial t}=D\left(\frac{\partial^{2}[A]}{\partial x^{2}}\right)$

The simulations of the cyclic voltammetry were made using a finite difference approach based on the Alternating Direction Implicit (ADI) method as detailed fully in ref [27]. The simulations were coded in $\mathrm{C}++$ with the Open Multi-Processing (OpenMP) library for parallel computing. The grid distances and the time step were studied and chosen to be sufficiently small to get an accurate calculation and full numerical convergence. All simulations were carried out on an Intel ${ }^{\circledR} 3.2 \mathrm{GHz}$ computer with 2.5 GB RAM and computing times of up to 240 minutes per cyclic-voltammetry simulation were required in order to obtain a highly accurate two dimensional simulation.

\section{Results and Discussion}

First, finite potential step chronoamperometry is considered using the ferrocyanide/ferricyanide $\left(\left[\mathrm{Fe}(\mathrm{CN})_{6}\right]^{4-} /\left[\mathrm{Fe}(\mathrm{CN})_{6}\right]^{3-}\right)$ redox couple as a model. Experiments were performed at glassy carbon electrodes of radii of $1.49 \pm 0.02 \mathrm{~mm}$ and $0.78 \pm 0.03 \mathrm{~mm}$ employing an aqueous solution of $9.50 \mathrm{mM}$ $\mathrm{K}_{4}\left[\mathrm{Fe}(\mathrm{CN})_{6}\right]$ and $0.50 \mathrm{M} \mathrm{KNO}_{3}$ as the electrolyte. Figure 1 shows the current-time transients resulting from a potential step from $-0.2 \mathrm{~V}$ vs SCE to $+0.35 \mathrm{~V}$ vs SCE, corresponding to a potential of zero current to mass transport limited oxidation of ferrocyanide. 

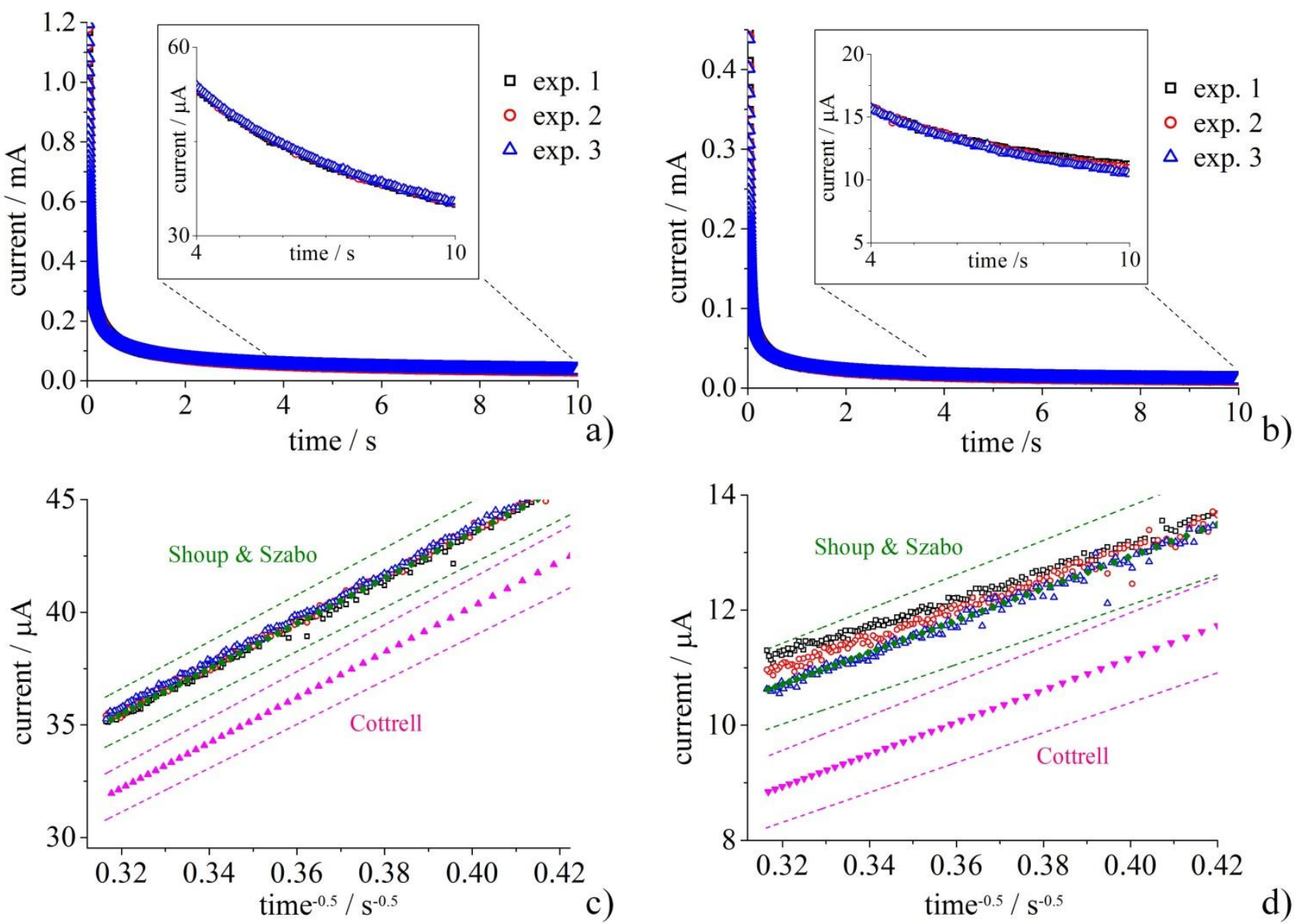

Figure 1: Experimental chronoamperograms $(I-t)$ recorded for 3 experiments (empty symbols) during the mass transport limited oxidation of $\left.\mathrm{Fe}(\mathrm{CN})_{6}\right]^{4-}$ at millimeter-sized glassy carbon electrodes of a) $r_{\mathrm{e}}=1.49 \mathrm{~mm}$ and b) $r_{\mathrm{e}}=0.79 \mathrm{~mm}$ and c,d) the comparison of experimental currents (empty symbols) with theoretical currents (solid symbols) as predicted by the Cottrell equation (eq. (1), pink) and the Shoup and Szabo equations (eq. (7)-(9), green); the dashed lines show the respective theoretical currents for maximum experimental variations according to the estimated errors in $D$ and $r_{\mathrm{e}}$; electrolyte: $9.50 \mathrm{mM} \mathrm{K}_{4} \mathrm{Fe}(\mathrm{CN})_{6}$, $0.5 \mathrm{M} \mathrm{KNO}_{3}$, potentiostated at $E=0.35 \mathrm{~V}$ vs SCE, time step for current measurement: $0.001 \mathrm{~s}$, temperature $=26.0 \pm 0.2^{\circ} \mathrm{C}$.

In order to fit the experimental data to the Cottrell equation (equation 1), it is necessary to know the electrode size and the diffusion coefficient of $\left.\mathrm{Fe}(\mathrm{CN})_{6}\right]^{4-}$ in the electrolyte at the experimental temperature. The former was measured (see Experimental) by optical microscopy to $1.49 \pm 0.02 \mathrm{~mm}$ and $0.78 \pm 0.03 \mathrm{~mm}$ radius for the two electrodes. The diffusion coefficient of $\left.\mathrm{Fe}(\mathrm{CN})_{6}\right]^{4-}$ was measured using a platinum micro electrode (radius $r_{\mathrm{e}}=4.8 \mu \mathrm{m}$ ) and calculated from the resulting limiting current according to:

$I_{\mathrm{ss}}=4 \mathrm{Fr} r_{\mathrm{e}} D[A]_{\mathrm{bulk}}$ 
for different temperatures in the range of $24{ }^{\circ} \mathrm{C}$ to $28{ }^{\circ} \mathrm{C}$. The measured steady-state voltammograms and the Arrhenius diagram derived from this data are plotted in Figs. 2a and 2b. Thus, the diffusion coefficient of $\left.\mathrm{Fe}(\mathrm{CN})_{6}\right]^{4-}$ at the used experimental conditions and the error associated with the estimated maximum temperature uncertainties during the chronoamperometric analysis were determined. Note that the obtained value for $D$ at $25^{\circ} \mathrm{C}$ is in agreement with the values reported for similar electrolytes [28] and the temperature dependency yields an activation energy $E_{\mathrm{a}}$ for diffusion of ca. $15.7 \pm 0.3 \mathrm{~kJ} \mathrm{~mol}^{-1}$, a value close to that expected from the temperature-dependent viscosity of water [29]. Based on this, the value of $D$ for the experimental temperature of $26^{\circ} \mathrm{C}$ for all chronoamperometric measurements was determined to be $7.68 \pm 0.03 \times 10^{-10} \mathrm{~m}^{2} \mathrm{~s}^{-2}$ (estimating an experimental temperature error of $\pm 0.2^{\circ} \mathrm{C}$ ).
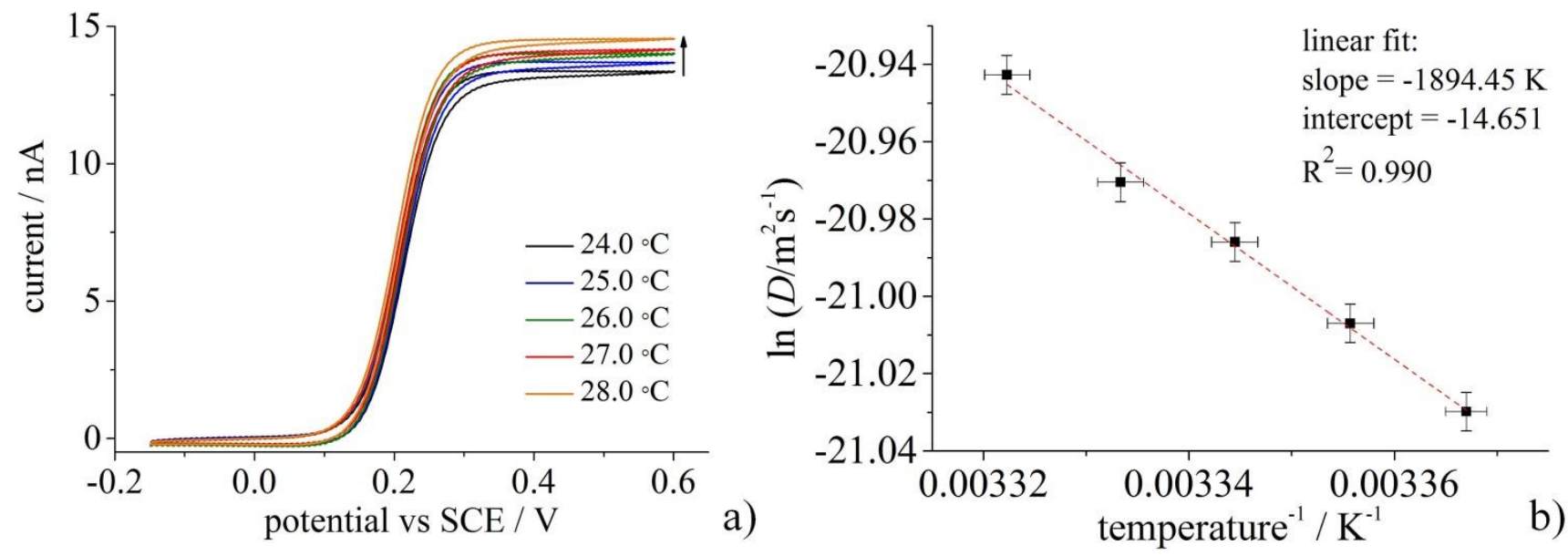

Figure 2: a) Steady-state voltammograms at a Pt micro disc electrode $\left(r_{\mathrm{e}}=4.8 \mu \mathrm{m}\right)$ recorded at different temperatures. b) Arrhenius plot (ln $D$ vs. $T^{1}$ ) of the derived diffusion coefficient of $\left.\mathrm{Fe}(\mathrm{CN})_{6}\right]^{4-}$ as a function of temperature; the linear fit (dashed line) of the data and the fitted parameters are given in the figure.

The values for the Cottrellian current (according to eq. (1), pink triangles) shown in Fig 1c and 1d and the expected error calculated from the possible uncertainties in the electrode size and diffusion coefficient (pink dashed lines) reveal that over the time scale from 0 to 10 seconds the experimental currents are clearly larger than predicted. The difference between the predicted and the observed current is greater for the smaller electrode (Fig. 1d) than for the larger one (Fig. 1c). Natural convection is not thought to play a dominant role at the timescale of interest $(\leq 10$ seconds), so the additional contribution of radial diffusion was considered as a plausible explanation for the augmented currents observed. Potential step chronoamperometry under these conditions has been extensively simulated and a particularly reliable calculation was reported by Shoup and Szabo [30]. The accuracy of their approach has been confirmed by

\footnotetext{
${ }^{\ddagger}$ The Arrhenius relation is $\ln D=$ constant $-E_{\mathrm{a}} \mathrm{R}^{-1} T^{-1}$, hence, the slope of the linear fit shown in Fig. $2 \mathrm{~b}$ provides the activation energy for the diffusion of $\left.\mathrm{Fe}(\mathrm{CN})_{6}\right]^{4-}$ in the electrolyte upon multiplication by $-\mathrm{R}$.
} 
many works[31-34]. For instance Klymenko, Svir et al. [35] presented their simulations on the basis of the Shoup and Szabo equations, which have been found well-suited for the analysis of experimental data $[36,37]$.

$I=4 \mathrm{~F} D r_{\mathrm{e}}[A]_{\mathrm{bulk}} \mathrm{f}(\tau)$

where the dimensionless time $\tau$ is defined as

$\tau=4 D t r_{\mathrm{e}}^{-2}$

For short dimensionless times $(\tau<1) \mathrm{f}(\tau)$ can be approximated as

$$
f(\tau)=\left(\frac{\pi}{4 \tau}\right)^{0.5}+\frac{\pi}{4}+0.094 \tau^{0.5}
$$

and for long times $(\tau>1)$

$f(\tau)=1+0.71835 \tau^{-0.5}+0.05626 \tau^{-1.5}-0.00646 \tau^{-2.5}$

The use of equations (7-9) to appropriately model the data presented in Fig. 1a and 1b suggests that the observed deviation from the purely Cottrellian behaviour can be attributed to radial diffusion effects. Figure $1 \mathrm{c}$ and $1 \mathrm{~d}$ show the excellent agreement between experiment and theory, validating that diffusiononly mass transport conditions were achieved in the experiment. It follows that electrodes of $0.78 \mathrm{~mm}$ and $1.49 \mathrm{~mm}$ radius are not sufficiently large to ensure pure one-dimensional diffusion over a time scale of several seconds. Note that such electrode dimensions are typical sizes of many commercially supplied 'macro' electrodes.

Given the significant contribution of radial diffusion to chronoamperometric currents at millimetre-sized electrodes, the effect of these contributions on cyclic voltammetry will be considered and quantified using simulations in the following section.

For this purpose the above-mentioned A/B redox couple was assumed to be fully electrochemically reversible and Nernst boundary conditions were applied to predict the current. Voltammetric curves in the presence and absence of radial diffusion were simulated and validated by comparison with analytical theory [27]. Figure 3 depicts the simulated voltammograms. 


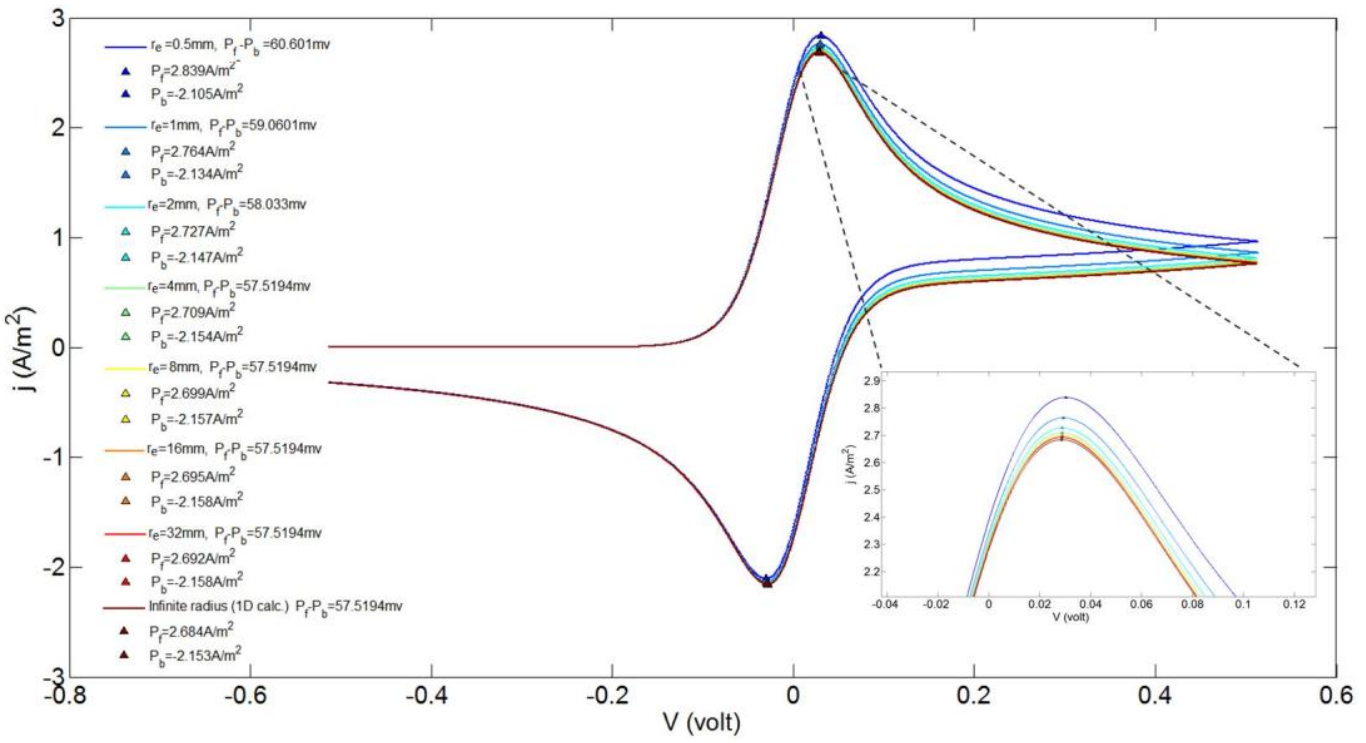

Figure 3: Voltammograms simulated assuming an electrochemically reversible redox couple A/B with Nernst boundary conditions and diffusion coefficients of $D_{\mathrm{A}}=D_{\mathrm{B}}=1 \times 10^{-9} \mathrm{~m}^{2} \mathrm{~s}^{-2}$. Voltammetric currents for various electrode sizes (radius $=r_{\mathrm{e}}$ ) are normalized by the area $\left(A=\pi r_{\mathrm{e}}^{2}\right.$ of the macro disc working electrode and the resulting current densities $(j)$ are shown. The inlay provides an enlarged view of the oxidative forward peak $\left(P_{f}\right)$ current densities $\left(j_{\mathrm{P}}\right)$.

A visible - and experimentally measureable - difference between the behaviour calculated using planar diffusion only and the full simulation of the finite electrode size is apparent. The 'reversibility' of redox couples is generally measured via the peak-to-peak voltage separation $E_{\mathrm{pp}}$. Table 1 summarises the variations of the peak current density $j_{\mathrm{P}}$ and $E_{\mathrm{pp}}$ values for different electrode sizes and scan rates, taking all other parameters as given in Figure 3. It is again evident that the electrodes of size of ca. 1 mm radius show significant deviations from the simple one-dimensional diffusion limit. Note that experimental observations of this kind in experiments could easily be miss-interpreted as electrode kinetics rather than geometric, mass transport effects. 
Table 1: Simulated voltammetric peak to peak separations and oxidative peak current densities for 'macro' disc electrodes of different radii in comparison to the results expected for a truly one-dimensional planar diffusion to an electrode of infinite size.

\begin{tabular}{|c|c|c|}
\hline $\begin{array}{c}\text { electrode radius } \\
r_{\mathrm{e}} / \mathrm{mm}\end{array}$ & $\begin{array}{c}\text { Peak-to-peak separation } \\
E_{\mathrm{PP}} / \mathrm{mV}\end{array}$ & $\begin{array}{c}\text { ox. peak current density } \\
j_{\mathrm{P}} / \mathrm{Am}^{-2}\end{array}$ \\
\hline 0.5 & 60.60 & 2.84 \\
\hline 1 & 59.06 & 2.76 \\
\hline 2 & 58.0 & 2.71 \\
\hline 4 & 57.52 & 2.70 \\
\hline 8 & 57.52 & 2.69 \\
\hline 16 & 57.52 & 2.69 \\
\hline 32 & 57.52 & 2.68 \\
\hline
\end{tabular}

\section{Conclusions}

If quantitative measurements are to be made in which experiments are coupled with theory then macro electrodes need to be selected with multi-millimeter radius to avoid contributions of 'edge effects' originating from radial contributions. Several commercially available 'macro' electrodes are likely to be too small to meet this requirement; rather electrodes of size not less than $4 \mathrm{~mm}$ radius are recommended for investigations in aqueous solutions. As diffusion coefficients of redox species are typically larger in organic solvents and smaller in many room temperature ionic liquids, larger and smaller minimum electrode sizes are required for a true 'macro' response in these cases, respectively. Alternatively, the use of microelectrodes may be preferred, especially for electro kinetic measurements.

\section{Acknowledgements}

KT was supported by a Marie Curie Intra European Fellowship (Grant Agreement no. [327706]) within the 7th European Community Framework Programme. SE and RGC acknowledge funding from the European Research Council under the European Union's Seventh Framework Programme (FP/2007-2013) / ERC Grant Agreement no. [320403]. 


\section{References}

1. Amatore CA, Deakin MR, Wightman M (1986) Electrochemical kinetics at microelectrodes Part 1. Quasi-reversible electron transfer at cylinders. J Electroanal Chem Interfacial Electrochem 206:23-36. doi: 10.1016/0022-0728(86)90253-6

2. Amatore C, Deakin MR, Wightman RM (1987) Electrochemical kinetics at microelectrodes: Part IV. Electrochemistry in media of low ionic strength. J Electroanal Chem Interfacial Electrochem 225:4963. doi: 10.1016/0022-0728(87)80004-9

3. Bond AM, Oldham KB, Zoski CG (1988) Theory of electrochemical processes at an inlaid disc microelectrode under steady-state conditions. J Electroanal Chem Interfacial Electrochem 245:71-104. doi: 10.1016/0022-0728(88)80060-3

4. Bond AM (1994) Past, present and future contributions of microelectrodes to analytical studies employing voltammetric detection. A review. Analyst 119:1R-21R. doi: 10.1039/AN994190001R

5. Scholz F (2009) Electroanalytical Methods: Guide to Experiments and Applications. Springer Science \& Business Media

6. Montenegro MI, Montenegro I, Queirós MA, Daschbach JL (1991) Microelectrodes: Theory and Applications: Theory and Applications. Springer Science \& Business Media

7. Mayrhofer KJJ, Strmcnik D, Blizanac BB, et al. (2008) Measurement of oxygen reduction activities via the rotating disc electrode method: From Pt model surfaces to carbon-supported high surface area catalysts. Electrochimica Acta 53:3181-3188. doi: 10.1016/j.electacta.2007.11.057

8. Concepcion JJ, Binstead RA, Alibabaei L, Meyer TJ (2013) Application of the Rotating Ring-DiscElectrode Technique to Water Oxidation by Surface-Bound Molecular Catalysts. Inorg Chem 52:10744-10746. doi: 10.1021/ic402240t 
9. Simonov AN, Kemppinen P, Pozo-Gonzalo C, et al. (2014) Aggregation of a Dibenzo[b,def]chrysene Based Organic Photovoltaic Material in Solution. J Phys Chem B 118:6839-6849. doi: $10.1021 / j p 501220 \mathrm{v}$

10. Nicholson RS, Shain I (1964) Theory of Stationary Electrode Polarography. Single Scan and Cyclic Methods Applied to Reversible, Irreversible, and Kinetic Systems. Anal Chem 36:706-723. doi: $10.1021 / \mathrm{ac} 60210 \mathrm{a} 007$

11. Nicholson RS, Shain I (1965) Theory of Stationary Electrode Polarography for a Chemical Reaction Coupled between Two Charge Transfers. Anal Chem 37:178-190. doi: 10.1021/ac60221a002

12. Cottrell FG (1902)Z Für Phys Chem 42:385.

13. Compton RG, Banks CE (2011) Understanding Voltammetry, 2nd ed. World Scientific

14. Fick A (1855) Ueber Diffusion. Ann Phys 170:59-86. doi: 10.1002/andp.18551700105

15. Fick A (1855) V. On liquid diffusion. Philos Mag Ser 4 10:30-39. doi: 10.1080/14786445508641925

16. Morris GP, Simonov AN, Mashkina EA, et al. (2013) A Comparison of Fully Automated Methods of Data Analysis and Computer Assisted Heuristic Methods in an Electrode Kinetic Study of the Pathologically Variable [Fe(CN)6]3-/4- Process by AC Voltammetry. Anal Chem 85:11780-11787. doi: $10.1021 /$ ac4022105

17. Bentley CL, Bond AM, Hollenkamp AF, et al. (2014) Applications of Convolution Voltammetry in Electroanalytical Chemistry. Anal Chem 86:2073-2081. doi: 10.1021/ac4036422

18. Simonov AN, Morris GP, Mashkina EA, et al. (2014) Inappropriate Use of the Quasi-Reversible Electrode Kinetic Model in Simulation-Experiment Comparisons of Voltammetric Processes That Approach the Reversible Limit. Anal Chem 86:8408-8417. doi: 10.1021/ac5019952

19. Norouzi P, Ganjali MR, Daneshgar P, Mohammadi A (2007) Fast Fourier Transform Continuous Cyclic Voltammetry Development as a Highly Sensitive Detection System for Ultra Trace Monitoring of Thiamine. Anal Lett 40:547-559. doi: 10.1080/00032710600964874 
20. Ebrahimi B, Shojaosadati SA, Daneshgar P, et al. (2011) Performance evaluation of fast Fouriertransform continuous cyclic-voltammetry pesticide biosensor. Anal Chim Acta 687:168-176. doi: 10.1016/j.aca.2010.12.005

21. Amatore C, Pebay C, Thouin L, et al. (2010) Difference between Ultramicroelectrodes and Microelectrodes: Influence of Natural Convection. Anal Chem 82:6933-6939. doi: 10.1021/ac101210r

22. Amatore C, Klymenko OV, Svir I (2012) Importance of Correct Prediction of Initial Concentrations in Voltammetric Scans: Contrasting Roles of Thermodynamics, Kinetics, and Natural Convection. Anal Chem 84:2792-2798. doi: 10.1021/ac203188b

23. Barnes AS, Streeter I, Compton RG (2008) On the use of digital staircase ramps for linear sweep voltammetry at microdisc electrodes: Large step potentials significantly broaden and shift voltammetric peaks. J Electroanal Chem 623:129-133. doi: 10.1016/j.jelechem.2008.06.022

24. Ward KR, Compton RG (2014) Quantifying the apparent "Catalytic" effect of porous electrode surfaces. J Electroanal Chem 724:43-47. doi: 10.1016/j.jelechem.2014.04.009

25. Ward KR, Gara M, Lawrence NS, et al. (2013) Nanoparticle modified electrodes can show an apparent increase in electrode kinetics due solely to altered surface geometry: The effective electrochemical rate constant for non-flat and non-uniform electrode surfaces. J Electroanal Chem 695:1-9. doi: 10.1016/j.jelechem.2013.02.012

26. Compton RG, Laborda E, Ward KR (2013) Understanding Voltammetry: Simulation of Electrode Processes. Imperial College Press, London

27. Eloul S, Compton RG (2014) Shielding of a Microdisc Electrode Surrounded by an Adsorbing Surface. ChemElectroChem 1:917-924. doi: 10.1002/celc.201400005

28. Konopka SJ, McDuffie B (1970) Diffusion coefficients of ferri- and ferrocyanide ions in aqueous media, using twin-electrode thin-layer electrochemistry. Anal Chem 42:1741-1746. doi: 10.1021/ac50160a042

29. Lide DR (2008) CRC handbook of Chemistry and Physics, 89th ed. Taylor \& Francis Group 
30. Shoup D, Szabo A (1982) Chronoamperometric current at finite disk electrodes. J Electroanal Chem Interfacial Electrochem 140:237-245. doi: 10.1016/0022-0728(82)85171-1

31. Heinze J (1981) Diffusion processes at finite (micro) disk electrodes solved by digital simulation. J Electroanal Chem Interfacial Electrochem 124:73-86. doi: 10.1016/S0022-0728(81)80285-9

32. Heinze J, Storzbach M (1991) Digital Simulation of Mass Transport to Ultramicroelectrodes. Conference Proceeding NATO Advanced Study Inst on Microelectrodes: Theory and Applications

33. Britz D, Oldham KB, Østerby O (2009) Strategies for damping the oscillations of the alternating direction implicit method of simulation of diffusion-limited chronoamperometry at disk electrodes. Electrochimica Acta 54:4822-4828. doi: 10.1016/j.electacta.2009.03.087

34. Britz D, Østerby O, Strutwolf J (2012) Minimum grid digital simulation of chronoamperometry at a disk electrode. Electrochimica Acta 78:365-376. doi: 10.1016/j.electacta.2012.06.009

35. Klymenko OV, Evans RG, Hardacre C, et al. (2004) Double potential step chronoamperometry at microdisk electrodes: simulating the case of unequal diffusion coefficients. J Electroanal Chem 571:211-221. doi: 10.1016/j.jelechem.2004.05.012

36. Xiong L, Aldous L, Henstridge MC, Compton RG (2012) Investigation of the optimal transient times for chronoamperometric analysis of diffusion coefficients and concentrations in non-aqueous solvents and ionic liquids. Anal Methods 4:371. doi: 10.1039/c1ay05667k

37. Paddon CA, Bhatti FL, Donohoe TJ, Compton RG (2006) Cryo-electrochemistry in tetrahydrofuran: The electrochemical reduction of a phenyl thioether: [(3- $\{[$ trans-4(Methoxymethoxy)cyclohexyl]oxy \}propyl)thio]benzene. J Electroanal Chem 589:187-194. doi: 10.1016/j.jelechem.2006.02.010 


\section{References}

1. Amatore CA, Deakin MR, Wightman M (1986) Electrochemical kinetics at microelectrodes Part 1. Quasi-reversible electron transfer at cylinders. J Electroanal Chem Interfacial Electrochem 206:23-36

2. Amatore C, Deakin MR, Wightman RM (1987) Electrochemical kinetics at microelectrodes: Part IV. Electrochemistry in media of low ionic strength. J Electroanal Chem Interfacial Electrochem 225:4963

3. Bond AM, Oldham KB, Zoski CG (1988) Theory of electrochemical processes at an inlaid disc microelectrode under steady-state conditions. J Electroanal Chem Interfacial Electrochem 245:71-104

4. Bond AM (1994) Past, present and future contributions of microelectrodes to analytical studies employing voltammetric detection. A review. Analyst 119:1R-21R

5. Scholz F (2009) Electroanalytical Methods: Guide to Experiments and Applications. Springer Science \& Business Media

6. Montenegro MI, Montenegro I, Queirós MA, Daschbach JL (1991) Microelectrodes: Theory and Applications: Theory and Applications. Springer Science \& Business Media

7. Mayrhofer KJJ, Strmcnik D, Blizanac BB, et al. (2008) Measurement of oxygen reduction activities via the rotating disc electrode method: From Pt model surfaces to carbon-supported high surface area catalysts. Electrochimica Acta 53:3181-3188

8. Concepcion JJ, Binstead RA, Alibabaei L, Meyer TJ (2013) Application of the Rotating Ring-DiscElectrode Technique to Water Oxidation by Surface-Bound Molecular Catalysts. Inorg Chem 52:10744-10746

9. Simonov AN, Kemppinen P, Pozo-Gonzalo C, et al. (2014) Aggregation of a Dibenzo[b,def]chrysene Based Organic Photovoltaic Material in Solution. J Phys Chem B 118:6839-6849

10. Nicholson RS, Shain I (1964) Theory of Stationary Electrode Polarography. Single Scan and Cyclic Methods Applied to Reversible, Irreversible, and Kinetic Systems. Anal Chem 36:706-723 
11. Nicholson RS, Shain I (1965) Theory of Stationary Electrode Polarography for a Chemical Reaction Coupled between Two Charge Transfers. Anal Chem 37:178-190

12. Cottrell FG (1902)Z Für Phys Chem 42:385

13. Compton RG, Banks CE (2011) Understanding Voltammetry, 2nd ed. World Scientific

14. Fick A (1855) Ueber Diffusion. Ann Phys 170:59-86

15. Fick A (1855) V. On liquid diffusion. Philos Mag Ser 4 10:30-39

16. Morris GP, Simonov AN, Mashkina EA, et al. (2013) A Comparison of Fully Automated Methods of Data Analysis and Computer Assisted Heuristic Methods in an Electrode Kinetic Study of the Pathologically Variable [Fe(CN)6]3-/4- Process by AC Voltammetry. Anal Chem 85:11780-11787

17. Bentley CL, Bond AM, Hollenkamp AF, et al. (2014) Applications of Convolution Voltammetry in Electroanalytical Chemistry. Anal Chem 86:2073-2081

18. Simonov AN, Morris GP, Mashkina EA, et al. (2014) Inappropriate Use of the Quasi-Reversible Electrode Kinetic Model in Simulation-Experiment Comparisons of Voltammetric Processes That Approach the Reversible Limit. Anal Chem 86:8408-8417

19. Norouzi P, Ganjali MR, Daneshgar P, Mohammadi A (2007) Fast Fourier Transform Continuous Cyclic Voltammetry Development as a Highly Sensitive Detection System for Ultra Trace Monitoring of Thiamine. Anal Lett 40:547-559

20. Ebrahimi B, Shojaosadati SA, Daneshgar P, et al. (2011) Performance evaluation of fast Fouriertransform continuous cyclic-voltammetry pesticide biosensor. Anal Chim Acta 687:168-176

21. Amatore C, Pebay C, Thouin L, et al. (2010) Difference between Ultramicroelectrodes and Microelectrodes: Influence of Natural Convection. Anal Chem 82:6933-6939

22. Amatore C, Klymenko OV, Svir I (2012) Importance of Correct Prediction of Initial Concentrations in Voltammetric Scans: Contrasting Roles of Thermodynamics, Kinetics, and Natural Convection. Anal Chem 84:2792-2798 
23. Barnes AS, Streeter I, Compton RG (2008) On the use of digital staircase ramps for linear sweep voltammetry at microdisc electrodes: Large step potentials significantly broaden and shift voltammetric peaks. J Electroanal Chem 623:129-133

24. Ward KR, Compton RG (2014) Quantifying the apparent "Catalytic" effect of porous electrode surfaces. J Electroanal Chem 724:43-47

25. Ward KR, Gara M, Lawrence NS, et al. (2013) Nanoparticle modified electrodes can show an apparent increase in electrode kinetics due solely to altered surface geometry: The effective electrochemical rate constant for non-flat and non-uniform electrode surfaces. J Electroanal Chem 695:1-9

26. Compton RG, Laborda E, Ward KR (2013) Understanding Voltammetry: Simulation of Electrode Processes. Imperial College Press, London

27. Eloul S, Compton RG (2014) Shielding of a Microdisc Electrode Surrounded by an Adsorbing Surface. ChemElectroChem 1:917-924

28. Konopka SJ, McDuffie B (1970) Diffusion coefficients of ferri- and ferrocyanide ions in aqueous media, using twin-electrode thin-layer electrochemistry. Anal Chem 42:1741-1746

29. Lide DR (2008) CRC handbook of Chemistry and Physics, 89th ed. Taylor \& Francis Group

30. Shoup D, Szabo A (1982) Chronoamperometric current at finite disk electrodes. J Electroanal Chem Interfacial Electrochem 140:237-245

31. Heinze J (1981) Diffusion processes at finite (micro) disk electrodes solved by digital simulation. J Electroanal Chem Interfacial Electrochem 124:73-86

32. Heinze J, Storzbach M (1991) Digital Simulation of Mass Transport to Ultramicroelectrodes. Conference Proceeding NATO Advanced Study Inst on Microelectrodes: Theory and Applications

33. Britz D, Oldham KB, Østerby O (2009) Strategies for damping the oscillations of the alternating direction implicit method of simulation of diffusion-limited chronoamperometry at disk electrodes. Electrochimica Acta 54:4822-4828 
34. Britz D, Østerby O, Strutwolf J (2012) Minimum grid digital simulation of chronoamperometry at a disk electrode. Electrochimica Acta 78:365-376

35. Klymenko OV, Evans RG, Hardacre C, et al. (2004) Double potential step chronoamperometry at microdisk electrodes: simulating the case of unequal diffusion coefficients. J Electroanal Chem $571: 211-221$

36. Xiong L, Aldous L, Henstridge MC, Compton RG (2012) Investigation of the optimal transient times for chronoamperometric analysis of diffusion coefficients and concentrations in non-aqueous solvents and ionic liquids. Anal Methods 4:371

37. Paddon CA, Bhatti FL, Donohoe TJ, Compton RG (2006) Cryo-electrochemistry in tetrahydrofuran: The electrochemical reduction of a phenyl thioether: [(3- $\{[$ trans-4(Methoxymethoxy)cyclohexyl]oxy\}propyl)thio]benzene. J Electroanal Chem 589:187-194. 